\title{
MQL with water in cylindrical plunge grinding of hardened steels using CBN wheels, with and without wheel cleaning by compressed air
}

\author{
Rodrigo de Souza Ruzzi ${ }^{1}$ - Rafael de Mello Belentani ${ }^{1} \cdot$ Hamilton José de Mello ${ }^{1}$. \\ Rubens Chinali Canarim ${ }^{1}$ - Doriana M. D'Addona ${ }^{2}$. Anselmo Eduardo Diniz ${ }^{3}$. \\ Paulo Roberto de Aguiar ${ }^{4} \cdot$ Eduardo Carlos Bianchi ${ }^{1}$
}

Received: 20 June 2016 / Accepted: 25 August 2016 /Published online: 31 August 2016

(C) Springer-Verlag London 2016

\begin{abstract}
Minimum quantity of lubricant (MQL) in grinding is an alternative for reducing abundant fluid flow and both environmental and health hazards when compared with conventional fluid application. In spite of the fact that MQL is considered an innovative cost-effective and environmentally friendly technique, when used in grinding its inadequate application can increase cutting temperature and wheel clogging, worsening surface roughness, and increasing geometric and dimensional errors. The present study aims to evaluate improvements in MQL in grinding using MQL + water (1:1, $1: 3$, and 1:5 parts of oil per parts of water), when compared to MQL without water and conventional cooling-lubrication technique. Wheel cleaning by compressed air was also tested, aimed for unclogging of the wheel pores. The tests were performed in a plunge cylindrical grinder with $\mathrm{CBN}$ wheel and workpieces of AISI 4340 for different feed rates. The ground workpieces were analyzed with respect to the surface roughness, roundness errors, microhardness, and microscopic changes. In addition, tangential cutting force and diametric
\end{abstract}

Paulo Roberto de Aguiar aguiarpr@feb.unesp.br

Rodrigo de Souza Ruzzi roruzzi@hotmail.com

Rafael de Mello Belentani

bianchiec50@gmail.com

Hamilton José de Mello

hamilton@feb.unesp.br

Rubens Chinali Canarim

rubenscanarim@hotmail.com

Doriana M. D'Addona

daddona@unina.it wheel wear were investigated. The results observed for the MQL plus water in the proportion of 1:5, with wheel cleaning system (at $30^{\circ}$ inclination angle of the air nozzle) were the best, when compared to MQL without water, and close to the conventional flood coolant, implying that this technique is a potential alternative for cooling-lubrication when applied properly.

Keywords Grinding $\cdot$ Cutting fluids $\cdot \mathrm{MQL} \cdot \mathrm{MQL}$ with water $\cdot$ Wheel cleaning

\section{Introduction}

Grinding is a complex machining process commonly used as a semi-finishing or finishing operation. Differently from machining process such as turning and milling, the abrasive grains of the grinding wheel, which perform the role of cutting

\author{
Anselmo Eduardo Diniz \\ anselmo@fem.unicam.br \\ Eduardo Carlos Bianchi \\ bianchi@feb.unesp.br
}

1 Department of Mechanical Engineering, São Paulo State University "Júlio de Mesquita Filho", Bauru Campus, Bauru, Sao Paulo, Brazil

2 Department of Chemical, Materials and Industrial Production Engineering, University of Naples Federico II, Piazzale Tecchio 80, Naples 80125, Italy

3 Department of Mechanical Engineering, University of Campinas, Campinas, Sao Paulo, Brazil

4 Department of Electrical Engineering, São Paulo State University "Júlio de Mesquita Filho", Bauru Campus, Bauru, Sao Paulo, Brazil 
edges, are irregular in shape and randomly distributed along the bond matrix [1].

In grinding operation, energy is consumed to form the chip by plastically deforming the workpiece and/or by overcoming friction because of the mechanical and chemical actions of wheel abrasives being plunging and sliding against the workpiece [2]. During the chip formation, most of the generated energy is converted into heat, raising the temperature within the cutting zone. If this temperature is not maintained within acceptable levels, thermal stresses occur in the workpiece and may compromise the ground surface and sub-surface integrity by cracking, warping, grinding burns, microstructural alterations, developing high residual tension, and generating dimensional inaccuracy [3].

For adequate dissipation of the high amount of heat generated, cutting fluids with high flow rates are usually applied [4]. However, the rotating grinding wheel generates an air barrier, harming proper fluid penetration in the cutting zone [5]. On the other hand, as already cited, high temperatures at the cutting zone can be very deleterious to the workpiece. Therefore, it is necessary to find a way for the fluid to penetrate into the cutting zone in order to protect the workpiece against all these damages.

In the grinding process, cutting fluid has three important functions: lubricating the contact between the workpiece and the grinding wheel, cleaning the chips in the cutting zone, and cooling of the workpiece [6]. It is not suitable not to use cutting fluid in grinding process, since it may cause thermal damages to the workpiece surface. Minimum quantity lubrication (MQL) stands as an alternative to dry grinding and conventional (flood coolant) lubricationcooling systems [7]. MQL is a technique where a minimal amount of liquid (frequently neat oil) is pulverized in a flow of compressed air and directed toward the cutting zone. Since it uses an amount of neat oil much smaller than flood coolant, grinding with MQL is considered a much more environmental friendly process. If part of the neat oil used in MQL is replaced by water, the process becomes even more environmentally friendly; since, besides decreasing the amount of oil used, it also minimize the mist of oil and air created in the grinding machine.

Despite the fact that MQL is efficient in the task of cutting zone lubrication, the application of low amounts of fluid in grinding harms wheel cleaning, increases wheel clogging by the small chips formed, and reduces the wheel cutting potential and performance [8]. Wheel clogging increases cutting forces, accelerates wheel wear, and harms the desired surface roughness. MQL does not promote adequate chip removal due to the fact that the grout formed by machined small chips mixed with MQL oil adheres to the wheel surface and clog its pores [9]. Therefore, even if MQL is an environmentally friendly technique due to its lower amount of fluid used, it is not easily applicable in grinding processes.
There has been increasing amount of work involving $\mathrm{MQL}+$ water, either presenting good results, when compared to MQL without water, in terms of workpiece surface roughness, roundness errors, and wheel wear [10], or even stating that MQL with water can be superior to conventional flood coolant [11]. Also, studies proved that MQL with water has a better cooling capacity than MQL without water, along with a slightly lower lubricating capacity, as stated by the grinding force results [12].

An effective grinding wheel surface cleaning can be observed when the MQL cooling-lubrication technique is used along with a $30^{\circ}$ incidence angle of compressed air jet. This combination of factors leads to improvements of output variables under investigation, such as surface roughness, roundness, wheel wear, acoustic emission, and microhardness, when compared with the MQL without cleaning, and even with the conventional flood coolant [13].

The present work aims to improve MQL application in grinding by combining effects of MQL with water along with wheel cleaning by compressed air. Water is added to the MQL oil (using the ratios 1:1,1:3, and 1:5 parts of oil per parts of water) in order to reduce the overall viscosity of the fluid and improve along with a compressed air jet directed to the wheel surface, grout removal, and overall results. In addition, MQL with water becomes more environmentally friendly reducing the amount of used oil. A wheel cleaning technique by compressed air was developed, proving itself a powerful technique for reducing wheel clogging; therefore, an improvement of the surface roughness, roundness errors, and wheel wear is observed. Thus, the MQL with wheel cleaning leads to a minor environmental impacts and health risks due to the great reduction of neat oil flow, without compromising the grinding process results [13].

\section{Materials and methods}

A CNC cylindrical plunge grinding machine equipped with a vitrified CBN (cubic boron nitride) grinding wheel with $350 \mathrm{~mm}$ outer diameter, $127 \mathrm{~mm}$ internal diameter, $20 \mathrm{~mm}$ width, and $5 \mathrm{~mm}$ abrasive material thickness was used. Ringshaped workpieces of AISI 4340 steel, quenched, and tempered $\left(54 \pm 2 \mathrm{HR}_{\mathrm{C}}\right)$, with dimensions of $54 \mathrm{~mm}$ outer diameter, $30 \mathrm{~mm}$ internal diameter, and $4 \mathrm{~mm}$ thickness were used for the tests. The wheel was dressed before every experimental test in accordance with the summarized conditions shown in Table 1 (adapted from [13]).

The MQL system used was comprised of an air compressor, a pressure controller, a flow measuring device, and a mixer nozzle. The flow rates of compressed air and lubricant fluid were separately controlled by the aforementioned MQL system, which had a built-in intermittent oil supply. A turbine flow meter was employed to monitor the compressed air flow 
Table 1 Grinding conditions

\begin{tabular}{|c|c|}
\hline Grinding mode & External cylindrical plunge grinding \\
\hline Grinding wheel & SNB151Q12VR2 (vitrified cubic boron nitride wheel) \\
\hline Wheel speed $\left(v_{\mathrm{s}}-\mathrm{m} / \mathrm{s}\right)$ & 30 (low for CBN wheels, but limited by the grinding machine) \\
\hline $\begin{array}{l}\text { Radial feed rate } v_{\mathrm{f}}-\mathrm{mm} / \mathrm{min}(\mathrm{specific} \\
\left.\text { material removal rate }-\mathrm{mm}^{3} / \mathrm{s}\right)\end{array}$ & $0.25(0.71), 0.50(1.41)$, and $0.75(2.12)$ \\
\hline Work speed $\left(v_{\mathrm{w}}\right)$ & $v_{\mathrm{w}}=0.58 \mathrm{~m} / \mathrm{s}$ \\
\hline Effective depth of cut $\left(a_{\mathrm{e}}\right)$ & $a_{\mathrm{e}}=1.2 \times 10^{-3} ; 2.5 \times 10^{-3} ; 3.7 \times 10^{-3} \mathrm{~mm} / \mathrm{rev}$ \\
\hline Cooling-lubrication conditions & $\begin{array}{l}\text { Conventional (flood coolant) conventional MQL and MQL with } \\
\text { wheel cleaning, with an incidence angle of } 30^{\circ}\end{array}$ \\
\hline Conventional cutting fluid & $\begin{array}{l}\text { Semi-synthetic vegetable oil-based emulsion at } 2.5 \% \\
\text { concentration }\end{array}$ \\
\hline MQL cutting fluid & $\begin{array}{l}100 \% \text { vegetable, biodegradable, viscosity of } 70 \text { centistokes } \\
\left(25^{\circ} \mathrm{C}\right)\end{array}$ \\
\hline Oil flow in MQL & $2.7 \times 10^{-8} \mathrm{~m}^{3} / \mathrm{s}$ \\
\hline Air pressure in MQL & $6.0 \times 10^{5} \mathrm{~Pa}$ \\
\hline Air flow in cleaning system & $8.0 \times 10^{-3} \mathrm{~m}^{3} / \mathrm{s}$ \\
\hline $\begin{array}{l}\text { Velocity of compressed air in cleaning } \\
\text { system }\end{array}$ & $470 \mathrm{~m} / \mathrm{s}$ \\
\hline Air pressure in cleaning system & $7.0 \times 10^{5} \mathrm{~Pa}$ \\
\hline Workpiece material & AISI 4340 steel, quenched and annealed $(54 \pm 2 \mathrm{HRc})$ \\
\hline Dresser & $\begin{array}{l}\text { Diamond cluster called "block grit" by Marinescu [14] _ area of } \\
15 \mathrm{~mm} \times 8 \mathrm{~mm} \times 10 \mathrm{~mm}\end{array}$ \\
\hline Dressing depth $\left(a_{\mathrm{d}}\right)$ & $a_{\mathrm{d}}=0.02 \mathrm{~mm}(12$ passes $)$ \\
\hline Sparkout time $\left(t_{\mathrm{s}}\right)$ & $t_{\mathrm{s}}=8 \mathrm{~s}$ \\
\hline Dressing speed $\left(v_{\mathrm{d}}\right)$ & $740 \mathrm{~mm} / \mathrm{min}$ \\
\hline
\end{tabular}

rate. The grinding wheel cleaning system consisted of an air compressor, flow and pressure meters, a flow distributor, and a nozzle. The cleaning nozzle was placed at $1 \mathrm{~mm}$ distance from the grinding wheel surface.

Each test consisted of $3900 \mathrm{~mm}^{3}$ of material removed using a specific set of grinding condition and was repeated three times. Three distinct cooling-lubrication techniques were applied: the conventional one (flood coolant), the MQL (using just neat oil with and without water), and the MQL plus a grinding wheel surface cleaning system.

For the experiments with flood coolant, semi-synthetic soluble oil ( $2.5 \%$ emulsion in water) was used at an output pressure of $0.4 \mathrm{MPa}$ and flow rate of $2.83 \times 10^{-4} \mathrm{~m}^{3} / \mathrm{s}$. For MQL and MQL plus water (1:1, 1:3, and 1:5 parts of oil per parts of water), a vegetable-based biodegradable oil was used. Table 1 shows the conditions used in the experiments.

MQL air pressure was $6.0 \times 10^{5} \mathrm{~Pa}$, and oil flow rate was $100 \mathrm{ml} / \mathrm{h}\left(2.7 \times 10^{-8} \mathrm{~m}^{3} / \mathrm{s}\right)$. The same fluid flow rate was used for the mixing oil plus water in all proportions. The nozzle design by da Silva [15] allows proper mixing, increasing fluid penetration.

Details of the experimental cooling-lubrication conditions employed in this investigation are shown in Table 2.

The wheel cleaning system was applied [13] using compressed air at a flow rate of $8.0 \times 10^{-3} \mathrm{~m}^{3} / \mathrm{s}$ and pressure of $7.0 \times 10^{5} \mathrm{~Pa}$. Compressed air was supplied by a dedicated designed nozzle for grout removal of the wheel pores
(Fig. 1). Also, $30^{\circ}$ was the air jet angle of incidence. This angle of incidence was chosen based in Oliveira [13] since it was the angle that provided the best results in terms of surface roughness, wheel wear, and other variables.

Surface roughness, Ra parameter, and measurements were conducted using a Taylor Hobson Surtronic 3+, with $0.25 \mathrm{~mm}$ cutoff. Roundness errors were measured by Taylor Hobson Talyround $31 \mathrm{C}$.

Grinding power was determined from the consumed energy of the grinding machine axis. Voltage and current signals from the spindle motor were converted into power signals, gathered and processed by National Instruments LabVIEW 7.1.

In order to measure diametric wheel wear, three workpieces were ground, using a method described in Oliveira [13]. An AISI 1020 steel cylinder $(35 \mathrm{~mm}$ diameter and $120 \mathrm{~mm}$ length) was used for printing the worn wheel profile. For profile measurement, Surtronic ${ }^{3+}$ was used, along with Taylor Hobson TalyMap.

Vickers workpiece microhardness was measured using a Mitutoyo HM-211 (300 g during $40 \mathrm{~s}$ ) in order to evaluate workpiece microstructural alterations after grinding. The workpiece surfaces were assessed by optical microscopy (Olympus BX-51). The preparation consisted of sanding, polishing, and etching with Nital $0.2 \%$, followed by ultrasonic cleaning.

Results presented for the outputs are averages of five measurements in different positions of each workpiece tested in 
Table 2 Cooling-lubrication conditions

\begin{tabular}{llll}
\hline Cooling-lubrication technique & Cutting fluid & Flow rate & Pressure \\
\hline MQL (oil) & Accu-Lube LB1000 & Air-34 m $3 / \mathrm{h}$ & $0.6 \mathrm{MPa}$ \\
& & Oil- $100 \mathrm{ml} / \mathrm{h}$ & \\
MQL (oil + water) & Rocol BIOCUT 9000 & Oil + water- $100 \mathrm{ml} / \mathrm{h}$ & \\
Conventional & ULTRACUT 370 & $17 \mathrm{l} / \mathrm{min}$ & $0.4 \mathrm{MPa}$
\end{tabular}

each condition. For each condition, three workpieces were ground.

\section{Results and discussion}

In this session, the results of the grinding experiments and their discussion after grinding the AISI 4340 steel with CBN wheel under various cutting conditions and various coolinglubrication techniques with and without cleaning of the grinding wheel are presented.

\subsection{Surface roughness}

The roughness analysis is important since the surface finish significantly affects workpiece fatigue strength when subjected to forces [4]. The superficial finish of the parts is directly related also to other material properties, such as friction coefficient, abrasion, lubrication capacity, thermal conductivity, mechanical resistance, among others [16]. Figure 2 compares the mean values of the Ra parameter $(\mu \mathrm{m})$ obtained after grinding with a CBN grinding wheel under different cooling-lubrications techniques, with or without cleaning the grinding wheel surfaces, for the three feed rates analyzed.
As it is shown in Fig. 2, roughness values increased with feed rate as expected, regardless the cooling-lubrication technique employed and the use of cleaning system. This is due to the fact that the higher the feed rate, the higher and faster will be the advancement of grinding tool against the workpiece. This results into a greater amount of material being cut from the surface of the workpiece. And also surface roughness increases due to the higher cutting forces produced by the fast advancement of the tool making vibrations to occur which deteriorates the surface finish [17].

It can be seen from Fig. 2 that the increase of water amount in the MQL flow improved surface roughness, regardless the feed rate, due to the overall lower viscosity. Wheel clogging is more prone to happen with pure MQL oil; in other words, when using MQL without water, the high viscosity liquid flow inside the MQL finds more difficulties to remove the chips, increasing the probability of workpiece scratching. Low viscosity oils (or oil plus water) have better penetrability at the cutting zone. When high viscosity fluids are used, the chips easily adhere to the wheel and produce more grout [18]. Cutting fluids strongly influences chip formation, since lubrication reduces friction and cools the cutting zone [7]. When lubrication is increased, plastic deformation decreases under the cutting edge of the abrasive grains, resulting in lower surface roughness. When friction is reduced, overall heat
Fig. 1 Positioning of the cleaning nozzle [8]

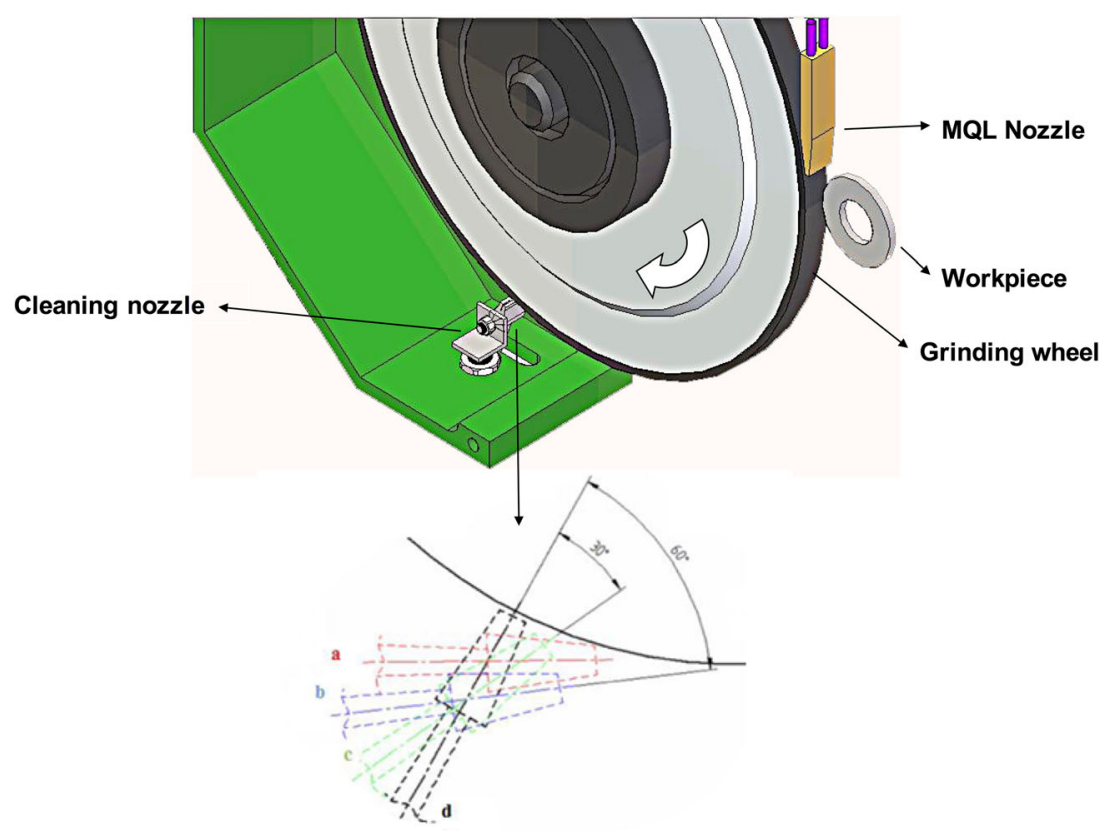


Fig. 2 Average surface roughness $(\mathrm{Ra})$ for each condition tested

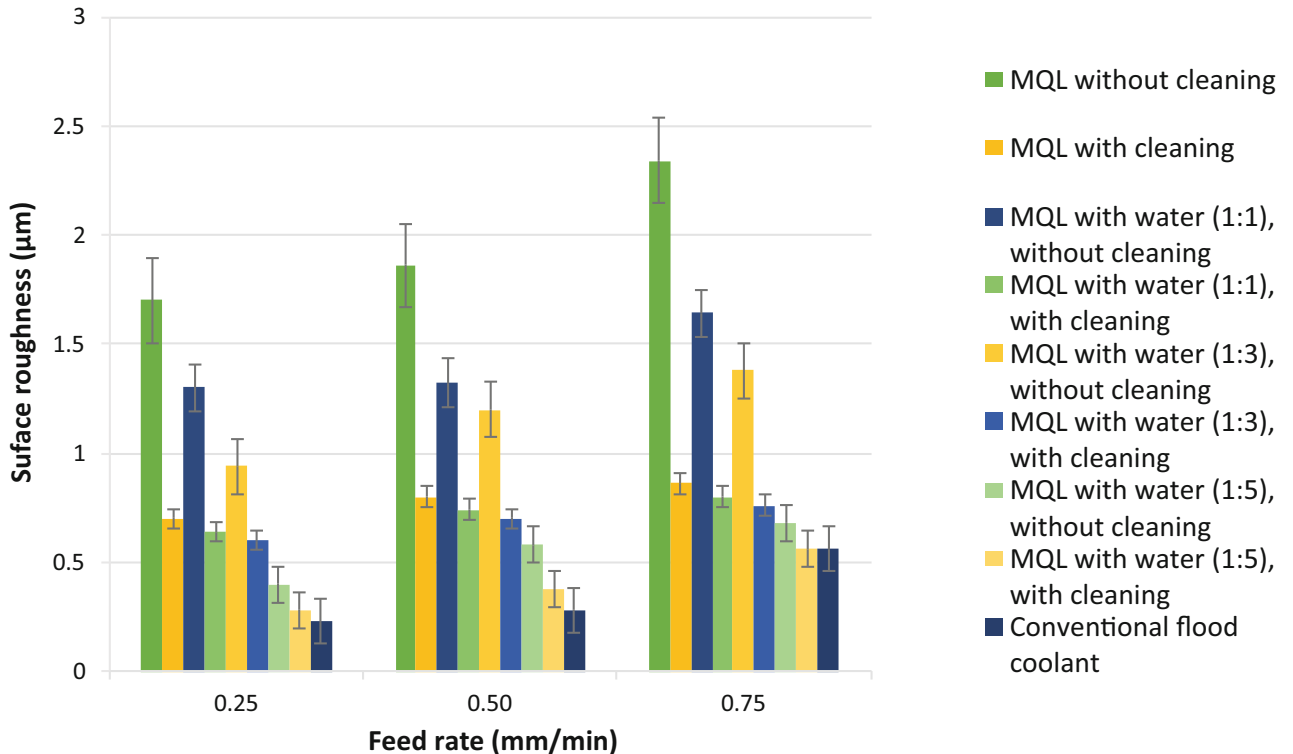

generation is also reduced. The use of integral oil in MQL harms efficient fluid penetration and, therefore, increases clogging. In other words, the supposed better lubrication provided by the high viscosity oil did not occur, when compared to MQL with water, because the fluid did not penetrate efficiently at the cutting zone. However, when a great amount of water is used in MQL, as the fluid penetrates at the cutting zone, lubrication occurs, even with less amount of oil in the fluid. Water thus reduce the overall viscosity and promote a more efficient lubrication, reducing surface roughness.

With regard to the wheel cleaning, roughness values decrease with the use of the wheel cleaning system for all situations. This is because the cleaning of the grinding wheel surface is able to minimize the clogging of the wheel caused by the chips and, therefore, to reduce surface roughness.

Figure 3 presents wheel clogging for the most critical conditions: MQL without water and MQL with water 1:5, using the highest feed rate $(0.75 \mathrm{~mm} / \mathrm{min})$, both without wheel cleaning.

It can be seen in this figure that the wheel used with MQL without water is full of chips adhered to it (shiny points in the picture). This result confirms that without the use of compressed air to clean the wheel, clogging occurs severely, and consequently, the results of surface roughness are worsened, for any of the tested feed rates. That occurs because the machined chips which clog wheel scratch against the workpiece. Cleaning by compressed air, however, promotes wheel cleaning by removal of the clogged grout (chips + MQL oil), reducing surface roughness. This result agrees with the results of da Silva [15]. For all tested feed rates, the increase of water amount in the MQL flow decreased the difference between surface roughness results with and without wheel cleaning, minimizing the influence of compressed air wheel cleaning. Therefore, when using lower amounts of water in MQL oil, wheel cleaning becomes even more necessary.

The conventional limits for surface roughness in grinding are 0.02-1.6 $\mu \mathrm{m}$ (Malkin, 2008). Then, conventional MQL (for each feed rate) and MQL with water $(1: 1)(0.75 \mathrm{~mm} /$ min), both without cleaning, should not be used. Regarding the other cooling-lubrication techniques, as the water content increases and lower feed rate values are used, wheel cleaning by compressed air becomes less necessary. Consequently, the
Fig. 3 Wheel clogging for a MQL with water 1:5 and $\mathbf{b}$ MQL without water, respectively, for $0.75 \mathrm{~mm} / \mathrm{min}$ (without wheel cleaning)
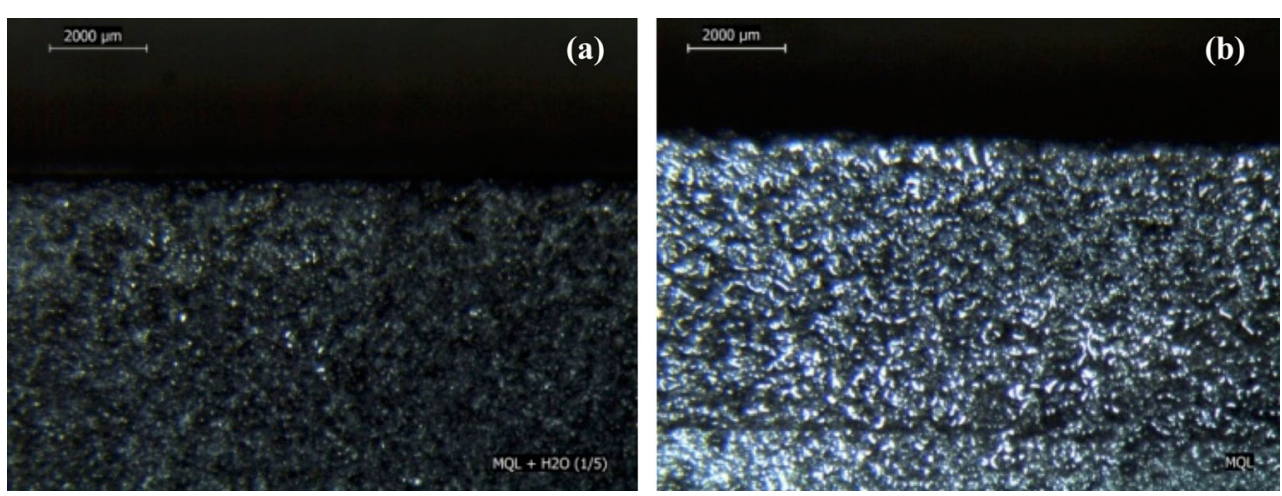
most adequate grinding condition in terms of workpiece surface roughness using MQL was obtained for MQL with water (1:5) with $0.25 \mathrm{~mm} / \mathrm{min}$ (with cleaning), since it presented results of surface roughness much lower than the usual values demanded for grinding process and close to conventional flood coolant, which still is the best condition when low value of surface roughness must be reached.

\subsection{Roundness errors}

Figure 4 presents the mean values of roundness errors after grinding with each tested condition. It can be observed that roundness values increased with feed rate as expected, irrespective the cooling-lubrication technique employed and the use of cleaning system. This can be explained by the increase in equivalent chip thickness and the specific material removal rate that occur with the increase of the radial feed rate which also result in a surface finish impairment [19].

With increasing water content in MQL, heat dissipation was improved and overall viscosity reduced, minimizing clogging, as already cited. Additionally, the lower friction caused by the better penetration of the fluid (even with lower content of pure oil and, so, lower lubrication capacity) promoted lower heat generation, reducing thermal distortions and roundness errors. Thus, for lower water contents, wheel cleaning becomes even more necessary.

The behavior of roundness error values is similar to those of surface roughness as shown in Fig. 4, that is the MQL cooling-lubrication technique without water and grinding wheel cleaning presented the highest values; while on the contrary, the lowest values were observed for the conventional technique. Results were substantially improved for MQL with water, the best condition among those using MQL being MQL with water (1:5), with wheel cleaning.
MQL without water and MQL with water provided results worse than for flood coolant, due to formation of grout, which clogged the wheel pores. It increases friction between wheel and workpiece and thus worsens the results for roundness errors.

Flood coolant is still the most efficient method, since it provided better cooling and reduced grout formation (as it is usually observed in MQL). Thus, cutting zone temperature was supposedly reduced, minimizing thermal distortions, allowing for higher dimensional and geometric accuracy, and consequently lower roundness error. However, several conditions using MQL with water, especially with wheel cleaning, presented roundness errors below $0.5 \mu \mathrm{m}$, even for high feed rates.

According to Tawakoli [20], the conventional coolinglubrication technique (with flood coolant) is better in cleaning the grinding wheel surface than the conventional MQL; therefore, the results obtained in this study are confirmed based on this statement.

Similarly, as for surface roughness, wheel cleaning reduced roundness errors, since clogging was reduced, minimizing friction, heat generation, and thermal distortions.

For any feed rate, higher contents of water in MQL provided lower difference between roundness errors, with and without wheel cleaning by compressed air.

\subsection{Diametric wheel wear}

Grind wheel wear is basically the frictional wear between abrasive grains and the workpiece [21]. Various lubricating fluids maintain a longer time of adhesion between abrasive grains and binding agent by reducing the friction in the grinding wheel/workpiece interface; this process effectively
Fig. 4 Average roundness errors for each condition tested

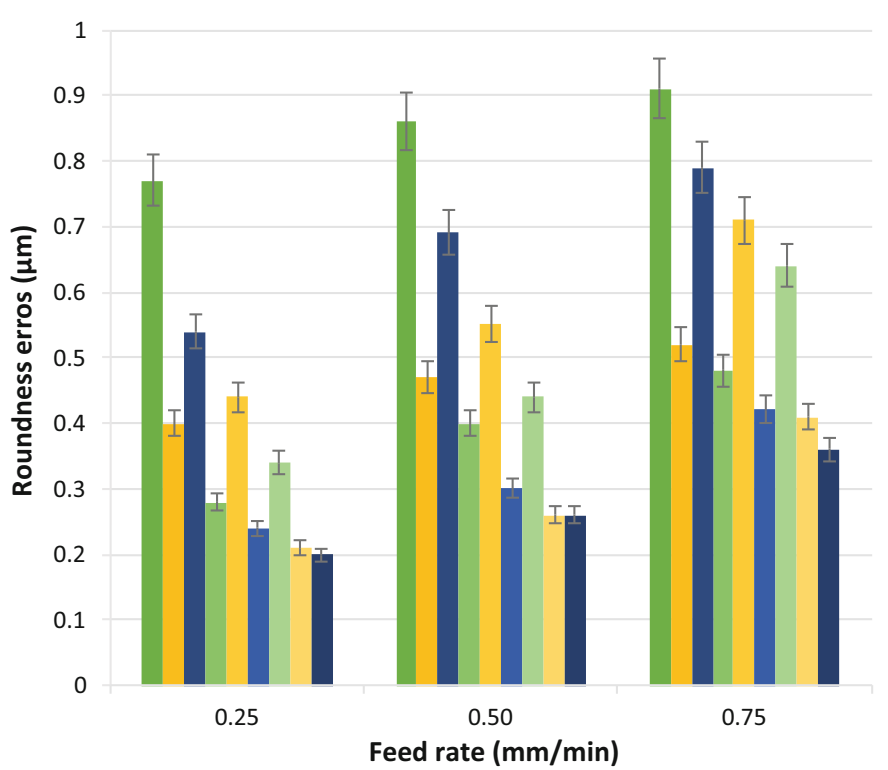

- MQL without cleaning

MQL with cleaning

nQL with water (1:1), without cleaning

MQL with water (1:1), with cleaning

MQL with water (1:3), without cleaning

MQL with water (1:3), with cleaning

$\square$ MQL with water (1:5), without cleaning

$\square$ MQL with water (1:5), with cleaning

- Conventional flood coolant 
prevents the falling off of abrasive grains and further decreases the grinding wheel wear [22].

The increased lubricity effect provided by the cutting fluid reduces grinding wheel wear by decreasing grain-workpiece and chip-bond friction, allowing abrasive grains to stay longer attached to the bond [4].

Figure 5 shows the diametrical abrasive wear values measured in a CBN wheel after grinding the AISI 4340 steel with each tested condition. From this figure, it can be seen that wear increased with feed rate in all the coolant techniques employed (with and without cleaning).

For lower heat dissipation at the cutting zone, higher losses of wheel bond strength occur, increasing wheel wear. Therefore, high mechanical loads and thermal degradation cause the diametric wheel wear [4]. As water additions for MQL provided higher cooling capacity, they also caused lower wheel wear.

Also for diametric wheel wear, in all feed rates, higher contents of water in MQL provided lower wear values due to increased cooling capacity. MQL without water, on the other hand, provided the worst results, while MQL with five parts of water and 1 part of oil was the best condition for MQL with water. For flood coolant, higher wear values were achieved when compared to MQL + water and wheel cleaning, since no efficient fluid penetration occurs when compared to MQL (with and without water). Thus, wheel cleaning becomes necessary for MQL with water. Flood coolant harms efficient penetration at the cutting zone increasing wheel wear.

Without wheel cleaning, diametric wheel wear values were higher. The difference between the wheel wear values with and without cleaning was higher than for surface roughness and roundness errors. In other words, wheel cleaning is even more significant to reduce wheel wear, than to reduce surface roughness and roundness errors. Moreover, the influence of wheel cleaning on the wheel wear was even higher than the influence of water presence in the MQL. This result indicates that the scratch of the chips stuck to the wheel with the workpiece is even more important for wheel wear than the better cooling capacity of the MQL plus water.

MQL with and without water (without wheel cleaning) increased wheel wear to values higher than those obtained with flood coolant, since wheel clogging was more intensely observed without wheel cleaning. This fact increased the mechanical and thermal loading on the wheel bond caused by the scratching of the chips against the workpiece, which may reduce its strength and detach grains, thus increasing wheel wear, since higher friction and heat generation are present.

\subsection{Grinding power}

Figure 6 shows the grinding power (W) obtained after grinding under various conditions. In this case, the results are opposite to those obtained for roughness and roundness errors. The more the water content in the MQL fluid, the higher was the grinding power.

Also, from Fig. 6, it can be seen that the grinding power increased with the increase of the fluid cooling capacity. Therefore, the lowest power was obtained with MQL without water and without cleaning, followed by MQL with water and, at last, by flood coolant. This can be explained by the fact that the more the cooling capacity, the lower the temperature of the workpiece in the cutting zone, causing the material to be more resistant and, consequently, more difficult to be removed by the abrasive grains, what caused the grinding power to be high.

The lowest values of grinding power observed for the MQL technique in relation to the conventional one, according
Fig. 5 Average diametric wheel wear for each tested condition

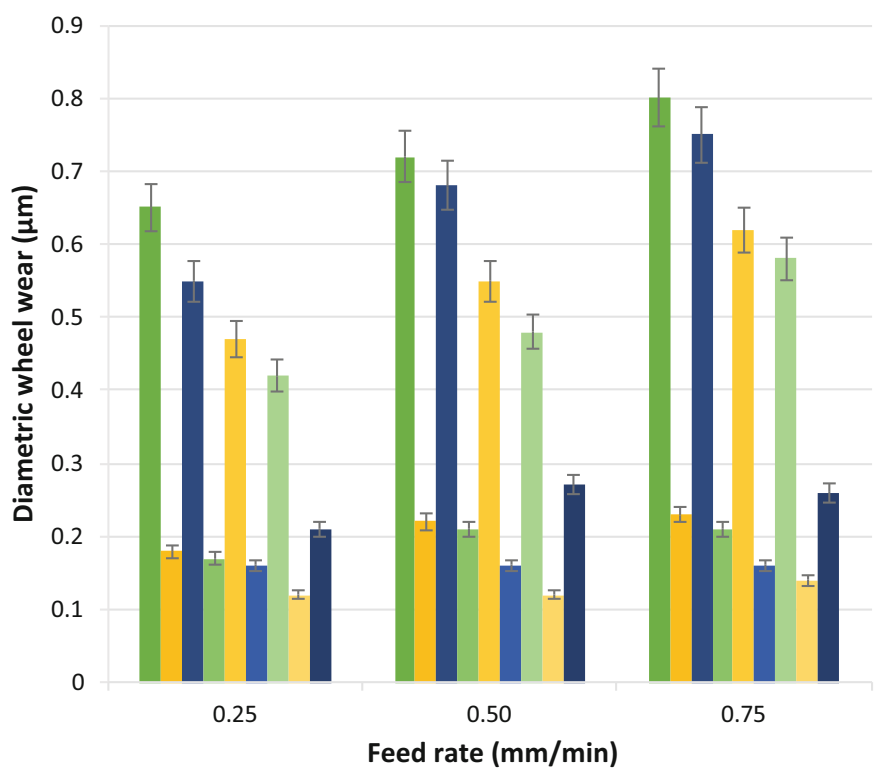

MQL without cleaning

MQL with cleaning

MQL with water (1:1), without cleaning

MQL with water (1:1), with cleaning

MQL with water (1:3), without cleaning

- MQL with water (1:3), with cleaning

MQL with water (1:5), without cleaning

MQL with water (1:5), with cleaning

- Conventional flood coolant 
Fig. 6 Average grinding power for each tested condition

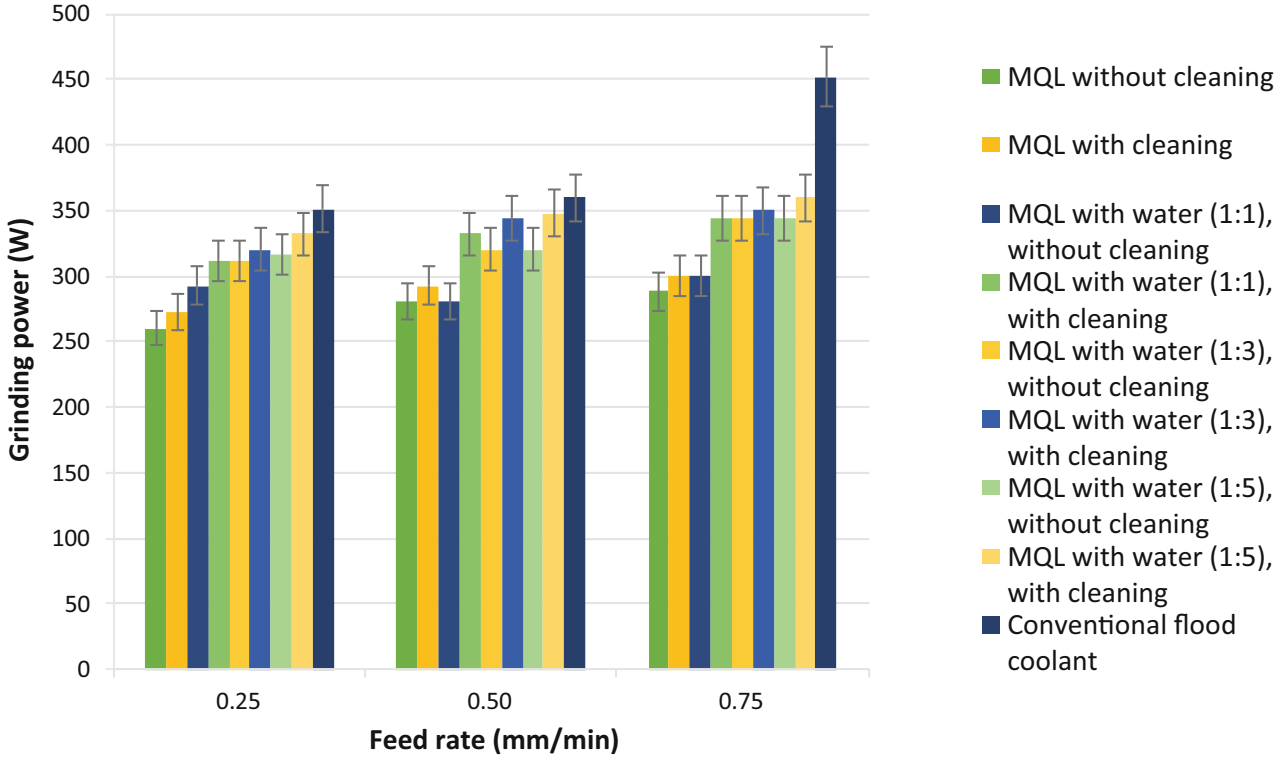

to Belentani [10], are due to the fact that the MQL is able to break up the air barrier built around the spinning grinding wheel while this is not possible in the conventional technique because of the low pressure applied to the coolant. Thus, the compressed air has the capacity to promote a more effective lubrication since it delivers the cutting fluid right into the cutting zone. The grinding power increases with the increase of the water amount in oil because of the lower lubrication capacity of the water compared to the oil, and higher amount of water implies in lower amount of oil when compared to the conventional MQL.

Since the conventional cooling-lubrication method is more effective in cleaning the grinding wheel surface and still presented the highest power values, it can be concluded that the insufficient lubrication in the cutting zone consumes more power than the friction between the chips and the workpiece caused by the grinding wheel surface clogging [10].

Wheel cleaning always increased grinding power. One hypothesis, to explain this occurrence, is that the incidence angle of the air jet $\left(30^{\circ}\right)$ created a reaction force on the wheel surface that removed efficiently the clogged grout, but also created a tangential component of this force against the wheel rotation, increasing grinding power.

\subsection{Optical microscopy and microhardness tests}

The optical microscopy analysis showed that no surface burns or tempering occurred on workpiece surfaces when flood coolant was used. Moreover, the average microhardness values obtained in the experiments with flood coolant for all feed rates were 693.1 Knoop, close to the value obtained for non-ground workpiece (711.8 Knoop).

For MQL without water and without cleaning, at the most critical condition $(0.75 \mathrm{~mm} / \mathrm{min})$, a white burn layer was formed (Fig. 7). A value of 849.1 Knoop was obtained, higher than 711.8 Knoop (non-ground workpiece) and 693.1 Knoop (flood coolant). During grinding of quenched and tempered steels, surface burns increase the workpiece hardness (Malkin, 2008), due to surface re-quenching, which is a consequence of the temperature increase reaching re-austenitizing levels. After that, with the quick cooling of the surface, formation of hard non-tempered martensite occurs.

White burns are harmful to the workpiece due to surface embrittlement and the increase of tensile residual stresses, which makes the workpiece prone to cracking, reducing wear, and fatigue strength [14].

For the experiments using MQL with wheel cleaning, the average surface microhardness was 662.8 Knoop, even lower than for flood coolant and for non-ground workpieces, proving that grinding on this case affected the surface integrity of the workpiece, however, not to the point of causing surface burns. Overtempering could have occurred, since surface temperature was not high enough to austenitize the structure, but enough for tempering the surface.

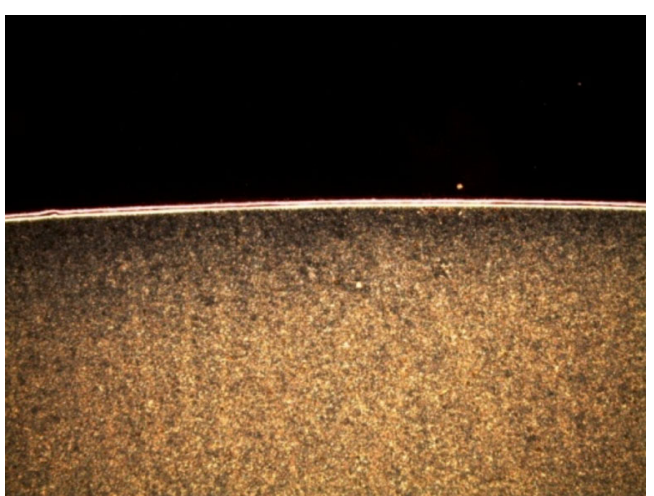

Fig. 7 Formation of white layer (MQL without water, without wheel cleaning, $0.75 \mathrm{~mm} / \mathrm{min}$ )-magnification $\times 10$ 
Fig. 8 Optical microscopy for MQL with water (1:5), without wheel cleaning $\mathbf{a} \times 10 ; \mathbf{b} \times 50$
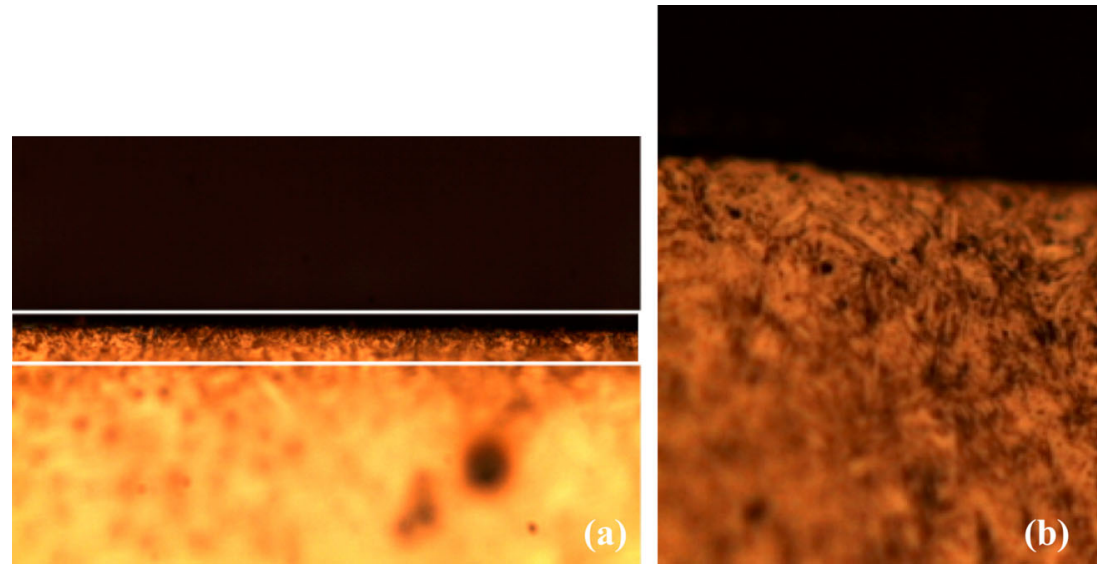

MQL with water (1:5) without cleaning (Fig. 8) promoted strain hardening. A value of 745.8 Knoop was found, lower than 849.1 Knoop (MQL without water, without wheel cleaning). By increasing the amount of water, better cooling can be achieved, reducing thermal damages. Since water has a lower lubricating capacity than MQL oil, lubrication can be less efficient, leading to strain hardening, thus increasing surface hardness slightly. Also the scratching of the workpiece against the wheel full of chips should have stimulated the plastic deformation of the workpiece surface and, consequently, the strain hardening.

For MQL + water (1:5) with wheel cleaning and the other conditions, no changes were observed, and no statistically significant differences could be observed when compared to the hardness obtained for the non-ground workpiece (which was 711.8 Knoop).

With that, it can be inferred that if the condition possess low cooling capacity and high level of wheel clogging (MQL without water and without cleaning), re-quenching occurs without tempering, and therefore, high hardness is obtained. If both cooling capacity and level of clogging are high (MQL with water 1:5, without wheel cleaning), temperature increase is smaller, and re-quenching (austenitizing) of the surface does not happen; however, overtempering occurs and the workpiece loses hardness. When good cooling capacity is achieved along with low level of clogging (MQL with water and wheel cleaning), temperature does not rise exceedingly, and the workpiece surface is not affected.

The best performance of the process, in terms of surface integrity, can be achieved by combining both water in MQL and wheel cleaning with compressed air. By using water and compressed air separately, surface integrity is not assured, since MQL with water does not provide efficient chip removal (which improves lubrication), and MQL with wheel cleaning does not provide efficient cooling, thus damaging the surface and causing variations in hardness, by strain hardening or overtempering. MQL without water and wheel cleaning is therefore not recommended, since it can cause high hardness and formation of white burns.

\section{Conclusions}

Based on the obtained results, it can be concluded that:

- For all the feed rates tested using wheel cleaning, increasing water content in MQL + water can greatly improve surface roughness and roundness errors, as well as wheel wear, when compared to MQL without water (and without wheel cleaning). For lower amounts of water in MQL oil, wheel cleaning by compressed air is even more necessary, in order to obtain better surface finish of the workpiece.

- Flood coolant is still the most efficient method, since it provides higher cooling effect and reduces grout formation (usually observed in MQL). With that, lower thermal distortions occur, allowing for higher dimensional and geometric accuracy.

- MQL (with and without water) demanded lower grinding power values and the conventional technique the highest values. When wheel cleaning was applied for MQL conditions, grinding power increased due to increasing forces on the wheel surface.

- For MQL without water (without wheel cleaning), a white burn layer was formed, with increased workpiece surface hardness.

- MQL with water and wheel cleaning with compressed air can greatly improve the overall quality of the workpieces, making it to be similar to that obtained conventional flood coolant application. The obtained results can thus be of benefit in advancing toward environmentally friendly machining and optimization of MQL application.

Acknowledgments This work was supported by the FAPESP (São Paulo Research Foundation) [grant numbers 2009/50965-7 (research 
assistance), 09/50964-0 (scientific initiation)] and the ITW Chemical Products Ltda - Brazil (providing the cutting fluid).

\section{References}

1. Tawakoli T, Hadad MJ, Sadeghi MH et al (2009) An experimental investigation of the effects of workpiece and grinding parameters on minimum quantity lubrication-MQL grinding. Int J Mach Tools Manuf 49:924-932. doi:10.1016/j.ijmachtools.2009.06.015

2. Sharma VS, Singh G, Sørby K (2014) A review on minimum quantity lubrication for machining processes. Mater Manuf Process 30: 935-953. doi:10.1080/10426914.2014.994759

3. Hryniewicz P, Szeri AZ, Jahanmir S (2000) Coolant flow in surface grinding with non-porous wheels. Int J Mech Sci 42:2347-2367. doi:10.1016/S0020-7403(99)00084-3

4. Malkin S, Guo C (2008) Grinding technology: theory and application of machining with abrasives, 2nd edn. Industrial Press, New York

5. Winter M, Bock R, Herrmann C (2013) Investigation of a new polymer-water based cutting fluid to substitute mineral oil based fluids in grinding processes. CIRP J Manuf Sci Technol 6:254-262. doi:10.1016/j.cirpj.2013.07.003

6. Ebbrell S, Woolley NH, Tridimas YD et al (2000) The effects of cutting fluid application methods on the grinding process. Int J Mach Tools Manuf 40:209-223. doi:10.1016/S0890-6955 (99)00060-7

7. Tawakoli T, Hadad M, Sadeghi MH et al (2011) Minimum quantity lubrication in grinding: effects of abrasive and coolant-lubricant types. J Clean Prod 19:2088-2099. doi:10.1016/j. jclepro.2011.06.020

8. Sadeghi MH, Haddad J, Tawakoli T, Emami M (2009) Minimal quantity lubrication-MQL in grinding of Ti-6Al-4V titanium alloy. Int J Adv Manuf Technol 44:487-500. doi:10.1007/s00170-0081857-y

9. Di Ilio A, Paoletti A (2000) Comparison between conventional abrasives and superabrasives in grinding of SiC-aluminium composites. Int J Mach Tools Manuf 40:173-184. doi:10.1016/S08906955(99)00061-9

10. Belentani RDM, Funes Júnior H, Canarim RC et al (2014) Utilization of minimum quantity lubrication (MQL) with water in CBN grinding of steel. Mater Res 17:88-96. doi:10.1590/S151614392013005000165
11. Nascimento WR, Yamamoto AA, Mello HJ et al (2015) A study on the viability of minimum quantity lubrication with water in grinding of ceramics using a hybrid-bonded diamond wheel. Proc Inst Mech Eng Part B J Eng Manuf 1-9. doi:10.1177/0954405415579016

12. Mao C, Tang X, Zou H et al (2011) Experimental investigation of surface quality for minimum quantity oil-water lubrication grinding. Int J Adv Manuf Technol 59:93-100. doi:10.1007/s00170-0113491-3

13. Oliveira DDJ, Guermandi LG, Bianchi EC et al (2012) Improving minimum quantity lubrication in CBN grinding using compressed air wheel cleaning. J Mater Process Technol 212:2559-2568. doi:10.1016/j.jmatprotec.2012.05.019

14. Marinescu ID, Rowe WB, Dimitrov B, Inasaki I (2004) Tribology of abrasive machining processes, 1st edn. William Andrew, Inc., Norwich

15. Silva LR, Bianchi EC, Fusse RY et al (2007) Analysis of surface integrity for minimum quantity lubricant-MQL in grinding. Int J Mach Tools Manuf 47:412-418. doi:10.1016/j. ijmachtools.2006.03.015

16. Silva LR, Corrêa ECS, Brandão JR, De Ávila RF (2013) Environmentally friendly manufacturing: behavior analysis of minimum quantity of lubricant-MQL in grinding process. J Clean Prod. doi:10.1016/j.jclepro.2013.01.033

17. Sohal N, Sandhu CS, Panda BK (2014) Analyzing the effect of grinding parameters on MRR and surface roughness of EN24 and EN353 steel. Mech Confab 3:1-6

18. Brinksmeier E, Heinzel C, Wittmann M (1999) Friction, cooling and lubrication in grinding. CIRP Ann Manuf Technol 48:581-598. doi:10.1016/S0007-8506(07)63236-3

19. Shaw MC (1996) Energy conversion in cutting and grinding*. CIRP Ann Manuf Technol 45:101-104. doi:10.1016/S0007-8506 (07)63025-X

20. Tawakoli T, Westkämper E, Rabiey M, Rasifard A (2007) Influence of the type of coolant lubricant in grinding with CBN tools. Int J Mach Tools Manuf 47:734-739. doi:10.1016/j.ijmachtools.2006.09.010

21. Wang Y, Li C, Zhang Y et al (2016) Experimental evaluation of the lubrication properties of the wheel/workpiece interface in MQL grinding using different types of vegetable oils. J Clean Prod. doi:10.1016/j.jclepro.2016.03.121

22. Silva LR, Bianchi EC, Catai RE et al (2005) Study on the behavior of the minimum quantity lubricant-MQL technique under different lubricating and cooling conditions when grinding ABNT 4340 steel. J Braz Soc Mech Sci Eng 27:192-199. doi:10.1590/S167858782005000200012 